\title{
The need for an Institute of Continuing Health Education
}

A $t$ a recent conference on continuing education involving many major US stakeholders and the CMAJ, participants agreed that our current system of continuing professional development is in dire need of a major overhaul. Currently, continuing medical education activities are, for the most part, sponsored by the pharmaceutical industry, which has a vested interest in promoting its products. This is big business: of the $\$ 2.6$ billion spent in the United States on accredited continuing medical education activities in 2006, $\$ \mathrm{I} .45$ billion (60\%) came from pharmaceutical and medical device manufacturers. ${ }^{1}$ Although there are no reliable data in Canada, there is also no evidence that the situation is any different here.

Worldwide, IMS, a private company specializing in pharmaceutical intelligence, reports that in 2004 the pharmaceutical industry spent US $\$ 27.7$ billion on promotional activities, and US $\$ 29.6$ billion on research and development. ${ }^{2}$

Some would argue that physicians are getting a good deal on their continuing professional education, so what is the problem?

First, the evidence suggests that education sponsored by the pharmaceutical industry frequently distorts the topic selection, embellishes the positive elements of studies ${ }^{3}$ and downplays the adverse effects. In effect, the industry focuses primarily on treatments and treatment-related issues at the expense of the larger therapeutic picture, including quality of care and patient safety not involving drugs, determinants of health, prevention and health promotion and other modalities of treatment. ${ }^{4}$

Second, there is no doubt that the current continuing education enterprise compromises the ethical underpinnings and the reputation of the medical profession. Physicians are seen as being aligned with the pharmaceutical industry and with its commercial priorities. We seem to have conveniently forgotten that the pharmaceutical industry is in business to make money, not to educate health professionals.

There is also the question of whether the type of education offered by the pharmaceutical industry actually works. Many of these heavily subsidized events use lectures and emphasize counting hours of credit, rather than measuring improved knowledge, competence, performance and, most importantly, clinical outcomes. Learning techniques, such as academic detailing, small group workshops and audit feedback, have demonstrated more substantial impact ${ }^{5}$ but are less frequently offered.

Finally, the current system focuses on physicians rather than on interdisciplinary teams. A team-based perspective is essential if our goal is to improve quality of care rather than market share. ${ }^{1}$

There have been repeated appeals for change, resulting in limited progress. The "No Free Lunch" campaign and other initiatives have raised awareness about the direct support of clinical teaching activities by the pharmaceutical industry. In Canada and the United States, research-based pharmaceutical industries have implemented voluntary codes of conduct designed to discourage or ban high-priced gifts. ${ }^{6}$ Some universities and academic departments have banned direct funding for continuing education activities such as rounds and have banned pharmaceutical companies from selecting topics and speakers. Nearly all conferences now require full disclosure of speakers' conflicts of interest. And organizations have also stepped up to the plate. For example, The Royal College of Physicians and Surgeons of Canada has implemented maintenance-of-certification and professional development programs that encourage a broad range of learning activities.

But still, our continuing medical education is driven by the pharmaceutical industry. Part of the responsibility resides clearly with physicians themselves. Over the years, the powerful pharmaceutical enticements have resulted in physicians believing that strong industry involvement is not only normal but also that they are entitled to receive the benefits. This culture of entitlement may be one of the most difficult obstacles to overcome.

To arrive in a healthier place, we need to disentitle physicians and adopt a more principled approach. The only way out is to take ownership and reinvent the system. Most importantly, given that the provision of efficacious continuing education is a quality-of-care and patient-safety issue, its focus must be on improving clinical knowledge, skills and attitudes as a means of improving clinical outcomes and quality of care by enhancing a practitioner's performance. In addition, continuing education activities must provide accurate information free from real or perceived biases. They should focus on themes and topics based on the needs of patients or health professionals; make greater use of a broad range of proven, effective adult learning techniques; include all health professionals; and be affordable, accessible and, where possible, integrated into clinical practice. Finally, all these initiatives should be easily implemented, monitored and accredited so that public trust is maintained. We might even consider publicly posting every physician's dossier of continuing medical education activities in the interest of optimal transparency.

Adopting these principles necessitates a radical change in our approach to funding. Many would argue for the need to completely ban all continuing medical education activities funded by the pharmaceutical industry. However, we might be best served by modelling the pharmaceutical industry's investments in continuing medical education similar to how we model its investments in research. One could imagine that the proposed Institute of Continuing Health Education would have many facets to its mandate (Box I). 
Box 1: Mandate for the proposed Institute of Continuing Health Education

- Set guidelines and standards for efficacious, unbiased continuing education

- Develop, support and promote interprofessional educational opportunities

- Monitor sources of all funds and set accreditation standards for continuing education providers

- Provide continuing education grants to accredited institutions

- Identify education and treatment gaps

- Develop more effective ways to educate health professionals

- Find new ways to integrate education into clinical practice

- Help health care professionals overcome barriers to lifelong learning

- Act as a central clearing house for continuing education for all health professionals

Under this approach, a portion of the profits from each new patent would be directed into an arm's-length organization, with additional funding from governments and the medical profession. In this vision, such an organization would bridge the current patchwork of continuing education providers and give a home, credibility and consistency to one of our most important activities.

The current system is unacceptable to self-regulated health professionals. It is time to stop the pharma-driven "free lunch" approach and place our continuing medical education system firmly in the hands of unbiased and qualified people, not corporations whose main concern is the bottom line.

To make this vision a reality, we call upon the Canadian Academies of Health Sciences, perhaps involving the US Institute of Medicine, to initiate a dialogue among all stakeholders. Getting thoughtful discussion underway is the first step in fixing a truly broken system maintained by our culture of entitlement.

\section{Paul C. Hébert MD MHSc}

Editor-in-Chief, CMAJ

With the Editorial-Writing Team (Matthew B. Stanbrook MDPhD, Barbara Sibbald BJ, Ken Flegel MDCM MSc, Noni MacDonald MD MSc and Amir Attaran LLB DPhil)

Competing interests: See www.cmaj.ca/misc/edboard.shtml.

\section{REFERENCES}

I. Fletcher SW. Chairman's summary of the conference. In: Hager M, editor. Continuing education in the health professions: improving healthcare through lifelong learning; 2007 Nov 28-Dec I; Bermuda. New York: Josiah Macy, Jr. Foundation; 2008.

2. Gagnon MA, Lexchin J. The cost of pushing pills: a new estimate of pharmaceutical promotion expenditures in the United States. PLoS Med 2008;5. Available: http://medicine.plosjournals.org/perlserv/?request=get-document\&doi=10.137I ljournal.pmed.005000I\#journal-pmed-005000I-boo4 (accessed 2008 Feb 27).

3. Wazana A. Physicians and the pharmaceutical industry. JAMA 2000;283:373-80.

4. Katz HP, Goldfinger SE, Fletcher SW. Academia-industry collaboration in continuing medical education: description of two approaches. J Contin Educ Heatlh Prof 2002;22:43-54.

5. Grimshaw JM, Shirran L, Thomas RE, et al. Changing provider behaviour: an overview of systematic reviews of interventions. Med Care 200I;39(Suppl 2):II2-45.

6. Sibbald B. US drug industry bans expensive freebies for MDs, Canada raises fines. CMAJ 2002;167:522. 